\title{
Invitación al estudio social e histórico de la música y la danza
}

\author{
Sergio Navarrete Pellicer
}

\section{$\mathrm{L}$} a publicación de este número dedicado a la antropología de la música tiene su origen en Río de Janeiro, Brasil, en las conversaciones que tuvimos varios antroipólogos y etnomusicólogos hace dos años durante el $36^{\circ}$ Congreso Mundial del Consejo Internacional de la Música Tradicional (ICTM). En aquel contexto intercambiamos y comparamos historia e ideas sobre el quehacer etnomusicológico en nuestros países, encontrando una diversidad de situaciones, con grandes semejanzas particularmente en la influencia de las políticas culturales nacionalistas de los gobiernos sobre los enfoques y el desarrollo de la etnomusicología en nuestros países durante el siglo pasado.

Reconocimos la importancia que tenía dicha convivencia internacional y nos propusimos trabajar conjuntamente para realizar proyectos que tuvieran un beneficio hacia las comunidades académicas de nuestros respectivos países.

Con este espíritu, y aprovechando el formato de revista temática de Desacatos, me propuse formalizar un recuento de lo que ha sido la etnomusicología en diversas partes del mundo, reuniendo un conjunto de textos de corte historiográfico y antropológico sobre la música y la danza, que tuviera fácil y rápido acceso a los lectores. Esta iniciativa se dirige, en primer lugar, a paliar las difi- cultades que tenemos los investigadores, musicólogos y antropólogos en nuestra labor formativa y docente para encontrar textos en lengua española que permitan a los estudiantes un acceso directo a debate y teoría etnomusicológicas relevantes y recientes en el plano internacional. Sin duda, este número es una invitación abierta a los estudios dentro de las ciencias sociales y humanísticas, y al público interesado en la cultura expresiva para que conozcan ejemplos de lo que ha sido la joven historia de la disciplina y su parentesco con la antropología.

\section{¿Etnomusicología o antropología de la música y la danza?}

En el número 7 de Desacatos (otoño de 2001) se discutió extensamente la pertinencia del concepto etnohistoria. De manera semejante, entusiastas y detractores del concepto etnomusicología, acuñado por Kunst en 1959, determinan su posición respecto a los sujetos que estudian y sobre lo que ha sido, es y debe ser la práctica de esta disciplina.

El prefijo "etno" ponía énfasis en el estudio de las culturas de las sociedades elegidas para el análisis de sus sistemas musicales. Durante varias décadas la disciplina

SERGIO NAVARRETE PELLICER: CIESAS-OaXaca.

Desacatos, núm. 12, otoño 2003, pp. 105-112. 
definió su campo de acción de acuerdo con dos criterios: el primero consistía en distinguir la música de la tradición occidental de aquellas "otras" tradiciones no occidentales. De esta manera, la etnomusicología comprendía el estudio de todas las culturas musicales del mundo excepto las de origen europeo. El segundo criterio intentaba hacer una separación entre la música de tradición escrita y la de tradición oral, dejando esta última como objeto de estudio de la etnomusicología. La oposición entre escritura y oralidad permitía establecer cómodamente la diferencia entre las tradiciones cultas y las folk y populares. En ambos criterios transpiraba la idea de la mayor complejidad técnica, sofisticación y superioridad de la música escrita y occidental sobre las demás. Estos criterios se repetían de igual manera entre los investigadores de los países periféricos en una suerte de colonialismo interno.

La necesidad del análisis sociocultural en los estudios musicológicos para entender los sistemas musicales de

106

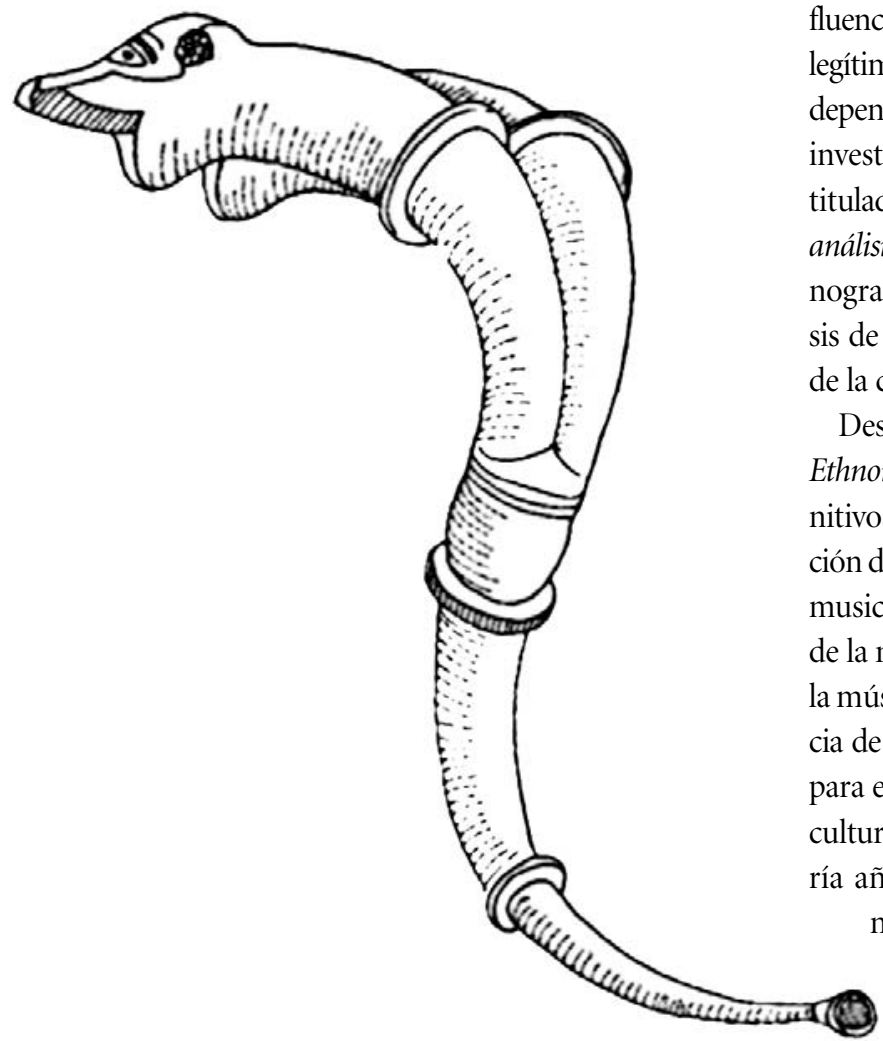

los "otros", derivó en una influencia creciente de las corrientes antropológicas sobre el estudio de la música. La mención de algunos encuentros fértiles entre la musicología y la antropología nos permitirán visualizar su relación de parentesco.

La primera propuesta teórico-metodológica en esta dirección fue el libro de Alan Merriam, Antropología de la música, publicado en 1964. En este libro el autor propone el estudio de tres grandes campos que son: 1) la conceptualización acerca de la música, 2) el comportamiento (físico, social y verbal) y 3 ) el sonido musical como producto del comportamiento que lo produce. Merriam planteaba que estos estaban relacionados, pues sin los conceptos acerca de la música el comportamiento no puede ocurrir y el sonido musical no puede ser producido. Esta propuesta funcionalista se aplicó en la realización de extensas monografías sobre tradiciones musicales y dancísticas exóticas, con la intención de dar cuenta de la relación entre la estructura social y las funciones que cumplían la música y la danza dentro de ésta. Asimismo, la influencia del relativismo cultural permitía tratar en forma egítima a las diversas culturas musicales de manera independiente y aislada. Un ejemplo ilustre de este tipo de investigaciones es sin duda el trabajo de John Blacking titulado Canciones infantiles de los venda: un estudio de análisis etnomusicológico, publicado en 1967. En estas monografías la vida ritual se convirtió en el locus del análisis de la cultura; el rito se asumió como el performance e la cultura en la música, la danza y el drama.

Desde una perspectiva práctica, Mantle Hood, en The Ethnomusicologist (1971), profundizó en los aspectos cognitivos del estudio de la música al centrarse en la definición del perfil del propio investigador. Sugería que el etnomusicólogo debía lograr el dominio práctico y teórico de la música de su propia cultura y al mismo tiempo de la música de la cultura que estaba estudiando. La exigencia de la bimusicalidad del investigador como condición para entender y poder traducir el lenguaje musical de la cultura que estudia fue una propuesta ideal que requeia años de entrenamiento musical. Su trabajo reconocía las diversidades culturales implícitas en los diferentes sistemas musicales y recomendaba una preparación para entender las distintas 
prácticas “performativas", los comportamientos y los procesos de conocimiento y transmisión de las tradiciones musicales, obligando al investigador a adentrarse y convivir prolongadamente con los portadores de dichas tradiciones.

Los estudios de cambios culturales motivados por las rápidas transformaciones que el sistema capitalista estaba generando en su expansión industrial alrededor del mundo, dieron lugar a explicaciones sobre la relación entre las tradiciones musicales campesinas y las de las elites urbanas y populares como un continuum de urbanización. Estudios como los de Turino $(1984,1993)$ sobre la movilidad social y el uso político-estratégico de las identidades sociales en los procesos de urbanización, mostraron la gran utilidad del análisis sociológico en la explicación de la formación de estilos musicales.

Por otro lado, el creciente acopio de información sistemática sobre los usos y funciones de la música y la danza, sobre las características de estructura, forma, estilo y cualidades del sonido y el movimiento rítmico intencional del cuerpo en una gran diversidad de regiones del mundo, revivió, desde el estructuralismo de Lomax (1968, 2001), la idea de comparar esos datos tras la búsqueda de universales musicales y del comportamiento humano.

La lingüística (Saussure), las teorías de la comunicación (Dell Hymes, 1974) y después la semiótica con sus modelos sobre los procesos de significación (Boiles, 1982; Chamorro, 1994) hicieron una gran contribución a los estudios de la música, primero, al reconocer que la música es comunicación; y segundo, al reconocer la existencia de un emisor y un receptor en dicho proceso. Estas simples consideraciones se han traducido en la necesidad de estudiar a las audiencias tanto como a los músicos y la música para encontrar el sentido y el valor como proceso comunicativo que esta última posee.

La importancia del análisis émico dentro de la antropología interpretativa ha fortalecido y renovado la tradición de los estudios sobre la cognición, dando lugar a un volumen considerable de etnografías musicales (Feld, 1990; Seeger, 1987; Chernoff, 1979; Robertson, 1979; Moisala, 1991; Koskoff, 1988; Stone, 1981, 1982; Basso, 1981) que explican, desde las categorías de los sujetos de es-

tudio, el papel de la música y del universo sonoro en la percepción y conceptualización filosófica y religiosa del mundo (sociedad y Naturaleza) y de su mantenimiento. En la antropología de la danza, Kaeppler (1972) y Hanna (1979) afirmaron que la perspectiva émica de los danzantes es una condición esencial en la definición del concepto de danza.

Se podría decir que la etnomusicología se ha desarrollado gracias a la diversidad de teorías y métodos que ha tomado de otras disciplinas o corrientes de pensamiento para aplicarlas al análisis antropológico de la música. Un buen ejemplo de esta colaboración interdisciplinaria es la teoría del performance, aplicada al estudio antropológico de la danza, la música, el teatro y el arte verbal. Los trabajos de Singer, Richard Bauman, Victor Turner, Richard Schechner y Eugenio Barba, por mencionar sólo algunos, se han convertido en estudios de cabecera de la etnomusicología. Esta conjunción afortunada de miradas hacia las artes "performativas" desde la antropología nos revela la íntima relación que existe entre estas manifestaciones estéticas en la vida ritual, sagrada y secular de todas las sociedades.

Sirva este recuento, no tanto para echar más leña al fuego de una discusión fútil, como apunta Olmos, entre musicólogos y antropólogos a propósito de la maternidad o paternidad de la disciplina, sino más bien para dar 


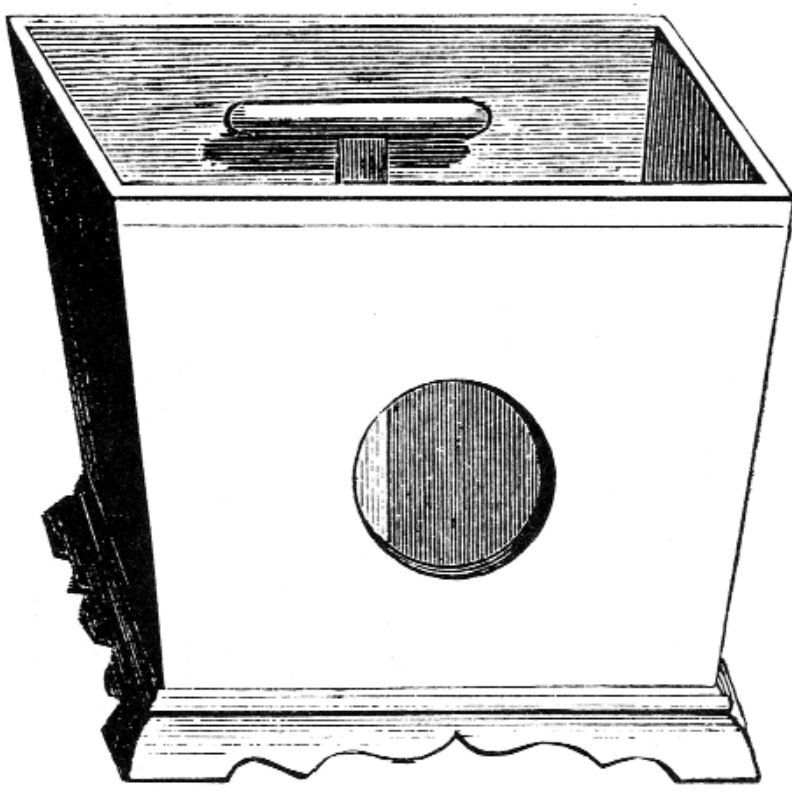

un reconocimiento a la antropología que ha sido suficientemente generosa y flexible para acoger el interés de otras disciplinas y compartir su desarrollo.

El contenido de esta sección de Desacatos está dividido en dos apartados. El primero se compone de dos estudios historiográficos sobre la etnomusicología en Brasil y China escritos por Suzel Reily y Yang Mu, respectivamente. El tercer artículo, de Miguel Olmos, también trata parcialmente la historiografía de la disciplina en México y sirve de pivote para la transición a la segunda parte en la que Olmos, Elizabeth Lucas, Larry Hilarian y Adrienne Kaeppler nos ofrecen, desde perspectivas distintas, análisis de ejemplos concretos de tradiciones musicales y dancísticas.

\section{Los estudios historiográficos}

Uno de los puntos comunes en los trabajos historiográficos sobre la disciplina en Brasil, China y México es el papel que han desempeñado las ideologías y políticas culturales nacionalistas de los Estados nacionales y de las elites dominantes en la conformación y desarrollo de la etnomusicología.
El artículo de Reily describe un panorama muy semejante al caso de México, considerando las diferencias en los antecedentes monárquicos y republicanos que habían vivido respectivamente Brasil y México en el siglo XIX. Esa similitud se desvanece en las décadas más recientes, dado que la etnomusicología en Brasil, a partir de 1985, denota una efervescencia, una actitud crítica y un desarollo envidiable comparado con México.

Reily señala cómo la emergencia de una conciencia de la cultura nacional cargada de sentimientos románticos, de patriotismo republicano, se convirtió en el motor del desarrollo de la disciplina desde finales del siglo XIX. En los inicios de la construcción de un proyecto de desarrollo nacional, los intelectuales brasileños veían la presencia indígena y negra como las causas del atraso del país y propusieron políticas de colonización y "blanqueamiento" de la población. Mientras en Brasil el "problema” principal eran los negros, en México eran los indios. La literatura etnomusicológica de ambos países está repleta de comentarios sobre el primitivismo de los instrumentos y de la música de los pueblos indígenas y negros. Poco después, el mito del mestizaje vino a redimir las culturas de los pueblos. El supuesto carácter y cultura del mestizo, "la raza cósmica" en el caso de México, pasaron a representar el alma de la nación y la solución a los problemas del subdesarrollo.

El análisis de Reily identifica en el discurso de los académicos la conformación de los estilos canónicos, en particular la modinha, el choro y más tarde la samba, como el canon de lo brasileño. Lo mismo podríamos decir del caso mexicano respecto al son mestizo, el jarabe y la canción ranchera, que recibieron además una gran difusión a través de la radio y de la industria cinematográfica.

Como dice la autora, en lugar de que la investigación fuese una esfera de evaluación crítica sobre la sociedad, se convirtió en un caballito de batalla para la construcción de la idea de nación y de sus estereotipos culturales. Proliferaron los estudios de rescate de tradiciones rurales que después eran ennoblecidas como fuentes de inspiración de obras de arte orquestales nacionalistas.

En su perspectiva sobre la etnomusicología brasileña más reciente, la autora considera la crítica al mito del 
mestizaje como la llave de la superación de la etapa nacionalista y observa una gran capacidad para poner a prueba, en la práctica, las teorías actuales de la etnomusicología, vigentes en los países del primer mundo. La madurez alcanzada en los estudios contemporáneos sobre la música en Brasil se refleja en el rico intercambio académico con la comunidad internacional y perfila a este país como uno de los centros de producción etnomusicológica más importantes del mundo junto a los Estados Unidos y Europa.

La línea principal que sigue el trabajo de Yang $\mathrm{Mu}$ es la crítica al pragmatismo político del Partido Comunista Chino en la manipulación de la investigación etnomusicológica desde su instauración en 1949 hasta finales de la década de 1970. El Partido impuso a los investigadores la tarea de encontrar la unificación de rasgos y características nacionalistas de la música en China que coincidieran con la ideología comunista y las necesidades de control del gobierno. El caso de este país es aún más crítico dada la política de cerrar las puertas al intercambio y a las influencias provenientes de Occidente.

Según el autor, el aspecto represivo en la implementación de estas políticas hizo que a pesar de la nueva apertura los investigadores hayan perdido el espíritu crítico que debe guiar toda investigación. Yang Mu apela, sin decirlo explícitamente, al habitus nacionalista de la sociedad china generado por una historia imperial sinocentrista de dos mil años. La política de Confucio de recolectar la tradición de los cantos como fuente de inspiración es comparada con la ideología marxista y el pragmatismo político del Estado. Hasta finales de la década de 1970, los resultados fueron la proliferación de estudios descriptivos sobre las tradiciones de música folclórica sin un aparato crítico, en los que se aplicaban criterios de selectividad que permitieran ajustar las tradiciones a cierta imagen de la cultura nacional.
El autor identifica dos áreas que se han desarrollado notablemente: los estudios históricos de la música, que excluyen por razones políticas los aspectos socioculturales, y los estudios de morfología de la música. Estos trabajos siguen aún el esquema del evolucionismo unilineal.

En su evaluación de la situación en China en las últimas dos décadas, el autor reconoce una apertura que ha permitido la realización de estudios de las tradiciones de las minorías étnicas que tienen sistemas musicales distintos al del grupo mayoritario han. Asimismo, continuando la fuerte tradición de estudios sobre las teorías antiguas de la música han aparecido trabajos comparativos respecto al sistema musical de Occidente y un interés por los estudios de la música popular que tiene influencias occidentales.

El trabajo de Miguel Olmos, en su parte historiográfica, describe el desarrollo de la disciplina al amparo de la folclorología, abanderada principalmente por Vicente T. Mendoza y el grupo de la Sociedad Folclórica de México. El autor plantea que la etnomusicología se ha desarrollado principalmente desde una plataforma institucional y que sus objetivos y resultados, sobre todo en la producción discográfica, han sido meramente de recopilación de información sobre las diferentes tradiciones musicales del país y resguardados en la capital.

Quienes hayan tenido la oportunidad de revisar la obra de Vicente T. Mendoza, Panorama de la música tradicional de México, publicada en 1956, podrán con-

firmar en su índice una visión evolucionista de la música de México. La sección de cantos indígenas actuales no responde a la secuencia cronológica del libro y se entiende como una continuidad de la música prehispánica. Esta sección es significativamente breve y se excluye del capítulo titulado "La música mexicana" que ocupa la mayor parte del libro y cuyo contenido se refiere a la música mestiza.

El mito del mestizaje como alma de la nación, del que habla Reily en el caso de Brasil, está también presente en la etnomusicología mexicana de aquella época. 


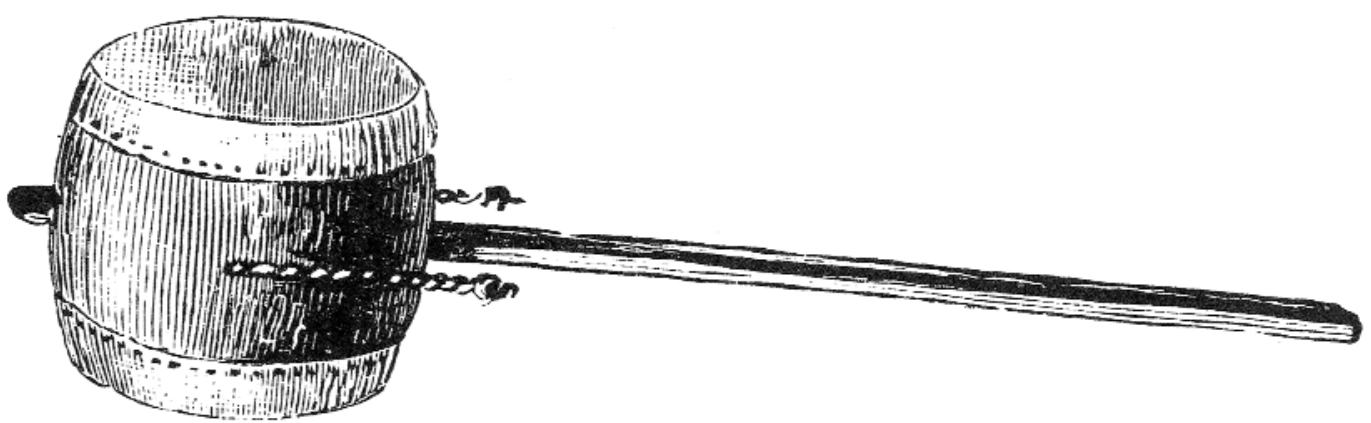

El trabajo anterior de Gabriel Saldívar titulado Historia de la música en México, publicado en 1934, aunque llama música popular a lo que Mendoza nombró soberbiamente música mexicana, también construye su obra basándose en el mito de la construcción biétnica, que en su hibridación da lugar a la vena popular de la música y en la que acomodó los vestigios de la influencia negra.

La obra coordinada por Jesús Estrada, titulada La música de México (1984), vuelve a cojear en su modelo histórico, y aunque con todo derecho coloca a la música indígena dentro del rubro de la música popular contemporánea - siguiendo las corrientes actuales que asumen lo folk o tradicional dentro de lo popular-, priva a la música popular y tradicional de cualquier perspectiva histórica, reservando ese derecho a la música llamada culta.

En este sentido, podemos decir que Olmos no hace un análisis de las causas que han llevado a la etnomusicología a tener un carácter tan descriptivo, como lo hace Reily, y acaba, a mi parecer injustamente, atribuyendo a la folclorología el hecho de que la etnomusicología no tenga una perspectiva más antropológica. De cualquier manera, cierto es que la etnomusicología en México no ha logrado una cooperación franca y sin prejuicios entre la musicología y la antropología.

En un breve interludio a su segunda parte, el autor plantea el papel del investigador que estudia la música, en particular la indígena. Sostiene que el etnomusicólogo es un traductor de códigos estéticos, y que para llevar a cabo dicha labor es necesario que conozca a fondo la cultura de los sujetos de estudio. En una sección final invita a los etnomusicólogos a trascender los límites que comúnmente se establecen entre la música tradicional y la popular en los estudios sobre la música indígena. La segunda parte de su trabajo tiene la virtud de ser una síntesis valiosa de las características principales de la música y la organología de la gran región chichimeca donde habitan diversos grupos indígenas de origen lingüístico uto-nahua y de grupos yumanos y seris.

\section{Los estudios de caso}

El trabajo de Elizabeth Lucas es un análisis semiótico y de análisis del discurso, sobre una canción llamada "Brasilhana", ejecutada en un festival musical de revitalización de la identidad gaucha brasileña en Río Grande do Sul, Brasil. Desde una perspectiva émica la autora va construyendo, con los testimonios de los participantes, el conflicto en torno a los significados del concepto de tradición que debe suponer el festival, generado entre los músicos, el compositor de esta canción y los productores del evento, por un lado, y la audiencia y la prensa, por el otro.

El análisis semiótico de la instrumentación, el estilo del canto, el género (samba-milonga) y la estructura musical de la canción, ilustrando los puntos de vista del compositor, llevan a Lucas a definir, por una parte, la propuesta musical como un intento transcultural de mediación de los símbolos regionales de la identidad hispánica de la región gaucha con los símbolos de la nacionalidad brasileña, conformados por las identidades múltiples y la diversidad cultural. Por la otra, identifica el malestar y el desencanto de la audiencia y la prensa sobre el festival como una reacción en defensa de los 
valores y la autenticidad de la cultura ranchera gaucha de la pampa. Lucas demuestra la importancia de la intermediación del discurso en la construcción de los valores sobre lo que significa la música que se produce y consume.

El estudio de Larry Hilarian sobre el laúd malasio es un buen ejemplo de la tradición etnomusicológica especializada en el estudio de la historia de la difusión y transformación de los instrumentos musicales y de los repertorios que los acompañan en este proceso. El trabajo de campo como parte de la investigación histórica aparece en su ensayo como un aspecto esencial para poder definir el objeto de estudio y la relación con otros instrumentos y tradiciones musicales. La comparación de fuentes y teorías sobre el origen del instrumento en la región está bien documentada, mostrando diferentes periodos históricos de colonización y expansión comercial de imperios y poblaciones árabes y portuguesas en distintos momentos de la historia de Malasia y la relación de estos procesos sucesivos desde el siglo IX con las influencias, pérdidas, recuperaciones y transformaciones del laúd o gambus malasio. La historia de este instrumento es un ejemplo de los procesos de larga duración en la transculturación de un producto cultural dentro de la historia colonial de los pueblos malasios. El trabajo se antoja como una invitación a los etnomusicólogos latinoamericanos para trazar la historia de los diferentes instrumentos de cuerda, de rasgueo y punteo que existen en el continente.

En los estudios de caso no podía faltar un artículo sobre la danza. El trabajo de Kaeppler hace justicia y trasciende el breve espacio que ocupa comparado con los trabajos sobre la música, pues se trata de un trabajo maduro que ofrece, en forma didáctica, conceptos teóricometodológicos para el estudio de la danza y los aplica al análisis de los bailes de la Polinesia. La danza —nos afirma la autora- podrá ser universal, pero no es un lenguaje universal. Es decir, que cada sistema dancístico comunica sólo a aquellos que tienen la competencia o preparación comunicativa en esta forma cultural y para una sociedad o grupo específico. La danza y su estructura se definen a partir de la perspectiva émica de sus productores, en los conceptos de movimiento de los danzantes de una tradición específica.
En su propuesta teórica Kaeppler hace una distinción entre los conceptos de estructura (sistema de movimiento) y estilo (la acción misma) que juntos establecen el concepto de forma. Para definir los elementos estructurales acude a la lingüística estructural, como lo hizo Levi Strauss en su análisis de mitos, y crea sus conceptos de kinema y morfokinema, ligados a su vez a unidades mayores que son los motivos y los coremas. Por otra parte, define el estilo como las formas de ejecutar o de poner en movimiento corporal los elementos de la estructura. Describe las características canónicas de las danzas polinesas e ilustra su concepto de estilo describiendo algunas diferencias estilísticas entre bailarinas de diferentes escuelas.

Con la iniciativa de este número se abre el espacio de Desacatos para futuras contribuciones antropológicas sobre la música y la danza.

\section{Bibliografía}

Barba, Eugenio, 1982, "Theater Anthropology”, The Drama Review, vol. 26, núm. 2, pp. 5-32.

Basso, Ellen B., 1981, "A 'Musical View of the Universe': Kalapalo Myth and Ritual as Religious Performance", Journal of American Folklore Society, núm. 94, julio-septiembre, pp. 273-291.

Bauman, Richard, 1977, Verbal Art as Performance, Waveland Press Inc, Illinois.

Béhague, Gerard (ed.), 1984, Performance Practice: Ethnomusicological Perspectives, Greenwood Press, Westport Connecticut.

Blacking, John, 1967, Venda Children's Songs. A Study in Ethnomusicological Analysis, Witwatersrand University Press, Johannesburg.

Boiles, Charles, 1982, "Processes of Musical Semiosis", Yearbook for Traditional Music, vol. 14, pp. 24-44.

Chamorro Escalante, Arturo, 1994, Sones de la guerra. Rivalidad y emoción en la práctica de la música purépecha, El Colegio de Michoacán, México.

Chernoff Miller, John, 1979, African Rhythm and African Sensibility. Aesthetics and Social Action in African $\mathrm{Mu}$ sical Idioms, The University of Chicago Press, Chicago y Londres.

Estrada, Julio (ed.), 1984, La música de México I. Historia 5. Periodo contemporáneo (1958-1980), Universidad Nacional Autónoma de México, México. 
Feld, Steven, 1990, Sound and Sentiment. Birds, Weeping, Poetics, and Song in Kaluli Expression, 2a. ed., University of Pennsylvania Press, Philadelphia.

Hanna, Lynne Judith, 1979, "Towards a Cross-cultural Conceptualization of Dance”, en John Blacking y Joann W. Kaeliinohomoku (eds.), The Performing Arts: Music and Dance, Mouton Publishers, The Hague, París y Nueva York.

Herndon, Marcia y Norma McLeod (eds.), 1980, The Ethnography of Musical Performance, Norwood Editions, Norwood.

Hood, Mantle, 1971, The Ethnomusicologist, McGraw, Nueva York.

Hymes, Dell, 1974, Foundations in Sociolinguistics: An Ethnographic Approach, University of Pennsylvania Press, Philadelphia.

Kaeppler, Adrienne, 1972, "Method and Theory in Analyzing Dance Structure with an Analysis of Tongan Dance", Ethnomusicology, vol. 16, núm. 2, pp. 173-217.

Koskoff, Ellen, 1988, "Cognitive Strategies in Rehearsal", Selected Reports in Ethnomusicology, vol. 7, Issues in the Conceptualization of Music, James Porter y Ali Jihad Racy (eds.), Department of Ethnomusicology, University of California, Los Ángeles.

Lomax, Alan, 1968, Folk Song Style and Culture: A staff Report on Cantometrics, American Association for the Advancement of Science, Publication 88, Washington D.C.

—_, 2001, "Estructura de la canción y estructura social", en Francisco Cruces et al. (eds.), Las culturas musicales: Lecturas de etnomusicología, cap. 12, Editorial Trotta.

Mendoza, Vicente, 1984, Panorama de la música tradicional de México, UNAM, México.

Merriam, Alan P., 1964, The Anthropology of Music, Northwestern University Press, Evanston.

Moisala, Pirkko, 1991, Cultural Cognition in Music. Continui- ty and Change in the Gurung Music of Nepal, Gummerus, Jyväskylä.

Robertson, Carol, 1979, "Pulling the Ancestors: Performance Practice and Praxis in Mapuche Ordering", Ethnomusicology, vol. XXIII, núm. 3.

Saldívar, Gabriel, 1987 [1943], Historia de la música en México, Gobierno del Estado de México, México.

Saussure, Ferdinand de, 1993, Curso de lingüistica general, 6a. ed., Editorial Fontamara.

Schechner, Richard, 1985, Between Theater and Anthropo$\log y$, University of Pennsylvania Press, Filadelfia.

Seeger, Anthony, 1987, Why Suyá Sing: A Musical Anthropology of an Amazonian People, Cambridge University Press, Cambridge.

Singer, Milton, 1958, "The Great Tradition in a Metropolitan Center: Madras", Journal of American Folklore, núm. 71, pp. 347-388.

Stone, Ruth M., 1981, "Toward a Kpelle Conceptualization of Music Performance", Journal of American Folklore, vol. 94, núm. 2, pp. 188-206.

— 1981, Let the Inside be Sweet: The Interpretation of Music Event Among the Kpelle of Liberia, Indiana University Press, Bloomington.

Turino, Thomas, 1984, "The Urban-Mestizo Charango Tradition in Southern Peru: A Statement of Shifting Identity", Ethnomusicology, vol. 28, núm. 1, pp. 253-270.

_ 1993, Moving Away from Silence: Music of the Peruvian Altiplano and the Experience of Urban Migration, University of Chicago Press, Chicago.

Turner, Victor, 1982, From Ritual to Theater: The Human Seriousness of Play, Performing Arts Journal Publications, Nueva York. , 1986, The Anthropology of Performance, PAJ Publications, A Division of Performing Arts Journal, Inc, Nueva York. 